\title{
Thermal Degradation of $\beta$-Carotene from Macauba Palm: Mathematical Modeling and Parameter Estimation
}

\author{
Pedro Prates Valério ${ }^{a^{*}}$, Amanda Lemette Teixeira Brandão ${ }^{\mathrm{b}}$, Jesus Maria \\ Frias Celayeta ${ }^{\mathrm{c}}$, and ERIKa Cristina $\mathrm{CREN}^{\mathrm{a}}$ \\ ${ }^{a}$ Chemical Engineering Department, Federal University of Minas Gerais - UFMG. Brazil \\ ${ }^{\mathrm{b}}$ Chemical Engineering and Materials Department, Pontifical Catholic University - PUC-RJ. Brazil \\ ${ }^{\mathrm{c}}$ Environmental Sustainability and Health Institute - Dublin Institute of Technology - DIT. Ireland \\ ${ }^{*}$ Corresponding author \\ pedroprates@ufmg.br \\ TEL.: +55-31-99345-1535
}

Received: 31 October 2018; Published online: 18 April 2021

Invited paper from the $5^{\text {th }}$ International ISEKI Food Conference - ISEKI Food 2018 - The Food System Approach - New challenges for Education, Research and Industry

\begin{abstract}
Worldwide, there is a current need for new sources of vegetable oils. The natural content of total carotenoids in Acrocomia aculeata palm oil (up to $378 \mu \mathrm{g} \cdot \mathrm{g}^{-1}$ ) surpasses that of many other tropical fruits, making it one of its main compositional characteristics. As far as can be verified, there is no available information on the degradation kinetics of carotenoids for A. aculeata oil, which is required to describe reaction rates and to predict changes that can occur during food processing. The present study considered prediction abilities that have emerged with the use of specific kinetic data and procedures to understand thermal processing better, as an essential unity operation. Two kinetic mechanisms were proposed to describe the overall thermal degradation of carotenoids in the oil; the first one consists of three reaction steps while the other presents only one-step reaction. Mass balance equations were numerically solved by a Backward Differentiation Formula technique. The kinetic parameters from both models were estimated through a hybrid optimisation method using the Particle Swarm Optimization and the Gauss-Newton method, followed by statistical analyses. The model with more than one reaction was shown to be overparameterized and was discarded. The model with a single reaction was highly suited to handle the experimental data available, and the dependency of its rate constant on temperature was expressed according to Arrhenius law. As far we know, this is the first time the kinetics of carotenoids thermal degradation in A. aculeata oil is investigated through modelling simulation.
\end{abstract}

Keywords: Parameter Estimation; $\beta$-Carotene; Mathematical Modeling

\section{Introduction}

From the perspective of extractive practices concerning oil crops, Acrocomia aculeata, known as macauba, is a palm tree widely dispersed in Brazil. Over the last few years, the food and chemical industries have been responsible for most of the growing demand for vegetable oils. In this context, the interest in macauba as a food product has increased due to factors such as the nutritional quality of the oils extracted from its edible parts. The industrial interest in macauba has also involved full use of its fruit to generate co-products with added value. The fruit 
mesocarp and kernel together correspond to approximately $47 \%$ (on dry basis) of the total fruit weight. Noticeably, the mesocarp contributes to around $60 \%$ (on dry basis) of the total oil content, with a predominance of oleic $\omega-9(53 \%)$ and linoleic $\omega-6(18 \%)$ acids. The kernel oil is predominantly saturated, with around $40 \%$ of lauric acid.

An adult Acrocomia aculeata palm fructifies almost throughout the year with productivity ranging from 4 to 6 tonnes of esculent oil per hectare. The crop has, accordingly, a similar productive potential to Elaeis guineensis, which is among the highest oil-yielding plants in the world (Evaristo et al., 2016). Considering that high yield has been an essential characteristic for the selection of commercial harvests, it has potential as an alternative oil crop that deserves further investigation (Rodriguez-Amaya, Kimura, Godoy \& Amaya-Farfan, 2008). Regarding the oil extracted from the fruit mesocarp, it contains no antinutritional factors and contains up to 378 $\mathrm{mg} . \mathrm{kg}^{-1}$ of total carotenoids, mainly $\beta$-Carotene (Nunes, Favaro, Galvani \& Miranda, 2015).

The carotenoids are essential pigments in fruits, these tetraterpenes $(\mathrm{C} 40)$ synthesised by plants are secondary metabolites, necessary for photosynthesis and to prevent photo-oxidation induced by light intensities. These functions are a consequence of the light-absorbing properties of their polyene chromophore (Oloo, Shitandi, Mahungu, Malinga \& Ogata, 2014; Rodriguez-Amaya, Rodriguez \& Amaya-Farfan, 2006; Schieber \& Carle, 2005). In general, carotenoids naturally exist as all-trans form. However, isomerisation of all-trans-carotenoids to cis forms is one of the major reactions of the compound's degradations. The critical step for losses of the component in vegetable oils remains related to the exposure to high temperature, light or pro-oxidant molecules. Indeed, the elevation of temperature during thermal treatments has been shown to dramatically increase corresponding degradation reactions rates (Achir, Randrianatoandro, Bohuon, Laffargue \& Avallone, 2010; Sampaio et al., 2013).

The intensity of the thermal treatment is a critical factor that has to be controlled to increase carotenoid retention in the macauba mesocarp oil. As an essential unit operation, the thermal processing influences both carotenoids bioaccessibility and the health-related attributes of vegetable oils (Nunes et al., 2015; Palmero et al., 2013; Rodriguez-Amaya et al., 2006).

Along with carotenoids products' identification, kinetic data become necessary to predict carotene loss on thermal degradation accurately. Kinetic evaluation is therefore required to derive necessary kinetic information for a system to describe the reaction rate as a function of experimental variables also predicting changes in a particular food system during processing. In general, most of the studies in real food report a first-order reaction on the concentration of trans$\beta$-carotene, in different systems, at different processing temperatures. Although zero-order equations have also been verified, the use of a firstorder kinetic is realistic in most cases. As far as we have knowledge there is no available information about thermal degradation kinetic modelling of neither $\beta$-carotene nor any other carotenoids from macauba oil (Achir, Penicaud, Avallone \& Bohuon, 2011; Ahmed, Shivhare \& Sandhu, 2002; Knockaert et al., 2012; Penicaud, Achir, Dhuique-Mayer, Dornier \& Bohuon, 2011).

Some studies in nonpolar solvents tested reaction orders superior to one for trans- $\beta$-carotene degradation and found a better fit of experimental data by linearisation or nonlinear regression methods. The superior orders may be explained by the competition with isomerisation reactions, which are also of importance in vegetable oils. Most of the kinetic models used to describe trans- $\beta$-carotene degradation are single response kinetic models. However, as the compound is supposed to generate various degradation products, the original reaction scheme can be complex to involve complex dynamics (Achir et al., 2010; Penicaud et al., 2011; Sampaio et al., 2013). Regarding the estimation of kinetic parameters for trans- $\beta$-carotene degradation, the rate constants $k\left(\mathrm{~s}^{-1}\right)$ can vary ranging from 0.00018 $\left(120^{\circ} \mathrm{C}\right)$ to $0.0015\left(180^{\circ} \mathrm{C}\right)$. The apparent activation energy $E_{a}\left(\mathrm{~kJ} \cdot \mathrm{mol}^{-1}\right)$ tends to range from 80 to 110 (Achir et al., 2010; Dhuique-Mayer et al., 2007; Henry, Catignani \& Schwartz, 1998; Sampaio et al., 2013).

The objective of the present study was to predict the thermal degradation of all-trans- $\beta$-carotene in Acrocomia aculeata oil through mathemat- 
ical modelling, emphasizing the importance of numerical predictions for practical applications. This study is an important step to comprehend better the kinetics of thermal degradation of macauba oil, which is a promising source of highquality raw materials.

\section{Materials and Methods}

\subsection{Crude Oil: Acrocomia aculeata}

Acrocomia aculeata fruit was collected from native palms with a maximum of five days after the fall in the Federal University of Minas Gerais - UFMG, located in the metropolitan region of Belo Horizonte, Minas Gerais, Brazil. The mesocarp and kernel portions were promptly separated from the fruit. Before the oil extraction, the mesocarp and kernel portions were thawed, airdried at $60{ }^{\circ} \mathrm{C}$ for 48 hours and comminuted in an electric grinder coupled to a stainless steel cup (Goula, 2013; Pimenta, 2010). For the present study, the samples consisted of edible oil mechanically obtained from the macauba mesocarp by a continuously operated Expeller ${ }^{\circledR}$ press, at $34^{\circ} \mathrm{C}$. Amber glass vials $(15 \mathrm{~mL})$ were filled to the maximum working volume with the samples, minimising the impact of light and oxygen intrusion by reducing the volume of headspace. Samples were stored at freezing temperature $\left(18^{\circ} \mathrm{C}\right)$ until the analysis to minimise possible rates and extents of enzymatic lipolysis, also concerning potential losses of antioxidants (Koidis \& Boskou, 2015; Parducci \& Fennema, 1978).

\subsection{Carotenoid Determination}

The HPLC analyses of carotenoids were carried out on a Shimadzu system (Shimadzu, Japan) equipped with a vacuum degasser, a quaternary pump and an autosampler (SIL-20A HT). A UVVisible photodiode array detector (SPD-M20A) was set in the range of $190-800 \mathrm{~nm}$ to analyse the chromatograms. Once $\beta$-carotene represent around $90 \%$ of the total carotenoids content in the A. aculeata mesocarp oil (Coimbra \& Jorge, 2012; Nunes et al., 2015), peaks were detected at $455 \mathrm{~nm}$, and the results were expressed as alltrans- $\beta$-carotene. The separation was achieved at $30{ }^{\circ} \mathrm{C}$ using a normal phase column (Phenomenex Luna Silica (2) 100A Si: $250 \mathrm{~mm} \times 4.6$ $\mathrm{mm}$ i.d., $5 \mu \mathrm{m}$ particle size) prior equilibrated with a flow of $0.1 \mathrm{~mL} \cdot \mathrm{min}^{-1}$. The mobile phase was n-hexane/isopropyl alcohol (97.0:3.0 v/v), the flow rate was maintained at $1.0 \mathrm{~mL} \cdot \mathrm{min}^{-1}$, and the elution remained isocratic until $26 \mathrm{~min}$. After every 10 injections of $20 \mu \mathrm{L}$, the column was reactivated with a solution of $10 \%$ isopropyl alcohol in n-hexane $(\mathrm{v} / \mathrm{v})$. The carotenoids were identified for each experimental condition by the combined use of their relative retention times and previously published UV/Vis spectra (Panfili, Fratianni \& Irano, 2004; RodriguezAmaya, Kimura et al., 2004). The concentrations (mg. $\mathrm{kg}^{-1}$ ) of carotenoids were expressed based on external matrix calibration (Sigma: St. Luis, MO). The spectrophotometric determination of total carotenoids (SD-TC) was performed using a Hach DR 2800 spectrophotometer (Hach, Loveland, CO, USA) as recommended by RodriguezAmaya, Kimura et al. (2004). The quantification (mg.kg-1) considered an absorption coefficient $\mathrm{A}_{1}^{1 \%}{ }_{\mathrm{cm}}$ of 2580 in high purity n-hexane (Zscheile, White, Beadle \& Roach, 1942).

\subsection{Thermal Degradation of all-trans- $\beta$-Carotene}

For all the experiments, the initial carotenoid concentration (determined according to item 2.2) was applied. $0.20 \mathrm{~mL}$ of oil ( $\rho$-macauba oil = $925.6 \mathrm{~g} \mathrm{~L}^{-1}$ ) was used. The thermal treatment that supported the Model Development and the Numerical Approach was carried out in triplicate, on a dry thermo-block (SAE 1020 steel DryBlock - CE-350; Cienlab). Aliquots of oil (2000 $\mu \mathrm{L}$ ) were placed into glass vials and inserted into the reactor. The aliquots were then heated until reaching the set temperature ( $\mathrm{t} 0)$. Thus, the heat treatments were assumed isothermal. The temperature monitoring (accuracy of $\pm 1{ }^{\circ} \mathrm{C}$ ) was performed based on digital thermometer probes placed into three control vials, also containing $2000 \mu \mathrm{L}$ of oil. The whole device was covered with aluminium foil to prevent carotenoid degradation by light. The thermal degradation kin- 
etics was carried out employing at least five time sampling points, at five temperatures: For 100 ${ }^{\circ} \mathrm{C}$, the experiment was run until $1500 \mathrm{~min}$ was reached; for $110{ }^{\circ} \mathrm{C}, 1440 \mathrm{~min}$; for $130{ }^{\circ} \mathrm{C}, 270$ $\min$; for $140{ }^{\circ} \mathrm{C}, 160 \mathrm{~min}$ and, finally, for $150{ }^{\circ} \mathrm{C}$, the experiment was conducted during $120 \mathrm{~min}$.

\subsection{Model Development and Numerical Approach}

A first-order kinetic mechanism (Mechanism I) with three irreversible reaction steps, represented in Equations (1) to (3), was initially chosen to be tested if it can represent well the thermal degradation of $\beta$-carotene in macauba oil.

$$
\begin{aligned}
& A \stackrel{k_{A B}}{\longrightarrow} B \\
& A \stackrel{k_{A C}}{\longrightarrow} C \\
& C \stackrel{k_{C B}}{\longrightarrow} B
\end{aligned}
$$

In the above equations, $A$ represents the alltrans- $\beta$-carotene, $B$ represents the oxidation and cleavage products (OCP), $C$ represents ciscarotenoids (mainly, 9 or 13 -cis- $\beta$-carotene). Also, $k_{A B}$ and $k_{C B}$ correspond to the rate constants for the thermal degradation of all-trans and cis- $\beta$-carotene, respectively. $k_{A C}$ corresponds to the carotene rate constant for the isomerisation of trans- $\beta$-carotene.

Assuming an isothermal, the material balances for all species involved in Mechanism I are represented by:

$$
\begin{gathered}
\frac{d[A]}{d t}=-k_{A B}[A]-k_{A C}[A] \\
\frac{d[B]}{d t}=k_{A B}[A]+k_{C B}[C] \\
\frac{d[C]}{d t}=k_{A C}[A]-k_{C B}[C]
\end{gathered}
$$

A second mechanism (Mechanism II) was also considered to be a candidate mechanism able to predict well the experimental data available from the thermal degradation of $\beta$-carotene. This second mechanism is a simplified version of the first one, and it is shown in Equation (7).

$$
A^{*} \stackrel{k_{A^{*} B}}{\longrightarrow} B
$$

In the above equation, $A^{*}$ represents the sum of all-trans and cis- $\beta$-carotene, and $k_{A * B}$ correspond to the rate constant for the thermal degradation of $\beta$-carotene.

Once more, assuming an isothermal, the material balances for all species involved in Mechanism II are represented by:

$$
\begin{gathered}
\frac{d\left[A^{*}\right]}{d t}=-k_{A^{*} B}\left[A^{*}\right] \\
\frac{d[B]}{d t}=k_{A^{*} B}\left[A^{*}\right]
\end{gathered}
$$

The ordinary differential equations resultant from the material balances (Equations (4) to (6) and (8) and (9)) were then solved using the BDF (backward differentiation formula) technique, as programmed in the DASSL code (Petzold, 1982). Parameter estimation was performed with the package ESTIMA, implemented in Fortran, using a hybrid optimisation method PSO (particle swarm optimisation) and GaussNewton algorithms (Brandao, Oechsler, Gomes, Souza \& Pinto, 2018; Schwaab, Biscaia, Monteiro \& Pinto, 2008). Five hundred particles were used, and two thousand iterations were performed with a numerical tolerance of 0.0001 for the objective function. Besides, a confidence level of $95 \%$ was considered, and all the parameters from Mechanisms I and II were estimated in their absolute form. The known weighted leastsquares function was used as the objective function in the present research, and it was defined as follows:

$$
\left.F_{o b j}=\left(y^{e}-y^{m}\left(x^{m}, \theta\right)\right)^{T} V_{y}^{(}-1\right)\left(y^{e}-y^{m}\left(x^{m}, \theta\right)\right)
$$

In the above equation, $y^{e}$ and $y^{m}$ are the vectors for the measured and predicted dependent variables, respectively; $V_{y}$ is the covariance matrix of the measured outputs (assumed to be diagonal); and $x^{m}$ and $v$ are the vectors of the measured independent variables and model parameters, respectively.

Experimental variances were obtained through replicates and are illustrated in the following sections. The experimental data used to estimate the parameters was the amounts of all-trans- $\beta$ carotene concentration presented at certain times $(A)$ divided by the initial amount of the caroten- 
oid $\left(A_{o}\right)$. Figure 1 shows the parameters estimation procedure performed in this study.

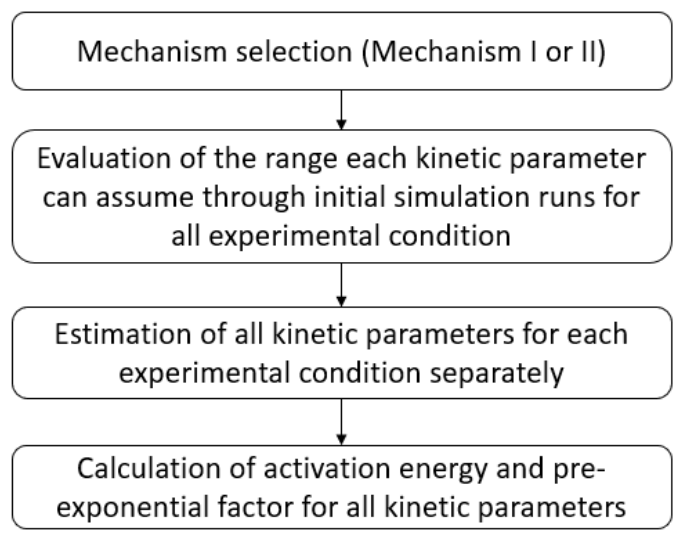

Figure 1: Flowchart of the parameter's estimation procedure

\section{Results and Discussion}

\subsection{The task and project brief}

The initial concentration of carotenoids was determined as $224.1 \mathrm{mg}$ for each $\mathrm{Kg}$ of macauba oil. Regarding the estimation procedure, it was conducted for each experimental condition separately, as shown in Figure 1. Table 1 shows the results for the objective function, the estimated parameter and respective uncertainty obtained when model derived from Mechanism I was considered. The experimental data and the model predictions within their uncertainties are shown in Figure 2.

From Table 1, except for reaction temperatures of 140 and $150{ }^{\circ} \mathrm{C}$, it is possible to observe that parameters uncertainties could not be calculated. Although all objective functions values were between the lower and upper limits of the $\chi 2$-distribution, the first model was not able to fit the experimental data available well since the model is over parametrised. At experimental conditions 140 and $150{ }^{\circ} \mathrm{C}$, practically all parameters can assume zero value, which shows they are not significative and, consequently, they can receive any value that won't change model prediction including zero or even negative values. Figure 2 shows that predicted and experimental profiles for the ratio $A / A_{0}$ during the reaction are in good agreement which was expected since the model has more parameters it requires, so more than one parameter combination can provide apparent good results. Since the parameters uncertainties for experiments at temperatures 100 , 110 and $130{ }^{\circ} \mathrm{C}$ could not be obtained through the parameter estimation procedure, as was done for the experiments done at 140 and $150{ }^{\circ} \mathrm{C}$, at least the parameters confidence regions for these three experimental conditions could be determined, providing an idea about the values the parameters $k_{A B}, k_{A C}$ and $k_{C B}$ can assume. So, Figure 3 shows the parameters confidence regions for experiments conducted at 100, 110 and 130 ${ }^{\circ} \mathrm{C}$ using the model derived from Mechanism I. In all confidence regions the estimated parameter values, presented in Table 1, are highlighted.

From Figure 3, it is possible to observe that, in all confidence regions, at least one kinetic parameter can assume zero value or even negative values. The regions are not well defined since parameter uncertainties are significantly high, also suggesting that the confidence region of parameters uncertainties become open (Schwaab et al., 2008), indicating estimability problems. The estimation of all parameter uncertainties simultaneously is unfeasible for these experimental conditions using Mechanism I. Based on what was said, the model derived from Mechanism I can be unconsidered as a candidate model to represent the experimental data available of thermal degradation of macauba oil.

The final objective function values for the five estimations done were between the lower and upper limits of the $\chi 2$-distribution. Therefore, according to the $\chi 2$ statistical test, the proposed model fitted experimental data well, and was suitable to predict the experimental data available. Besides, all parameters uncertainties could be calculated, and they are smaller than the estimated parameters. Figures 4 shows that simulated and experimental trajectories for $A / A o$ during the reaction are in very good agreement for runs conducted at 100, 110, 130, 140 and $150{ }^{\circ} \mathrm{C}$. The model predictions adequately fitted the experimental data measured during reactions, respect- 
$166 \mid$ Valério et al.

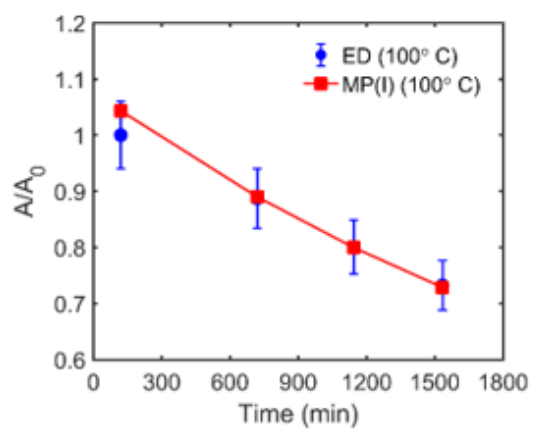

(a)

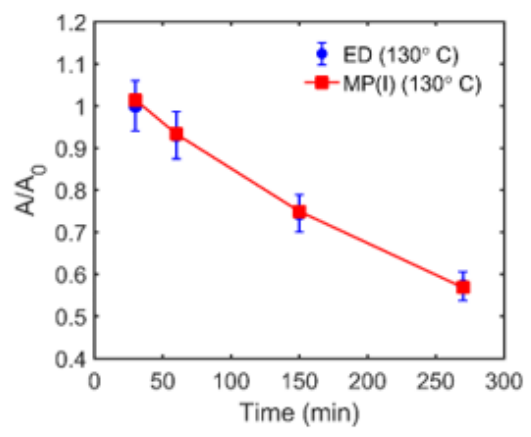

(c)

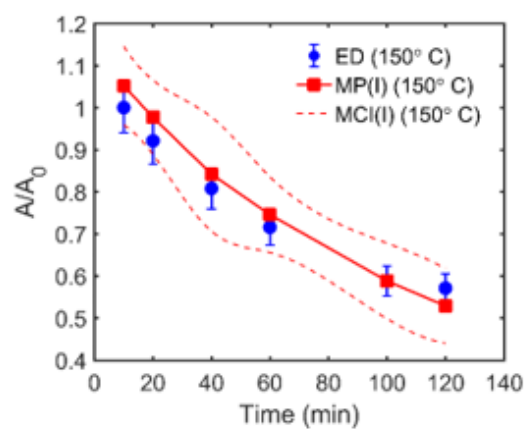

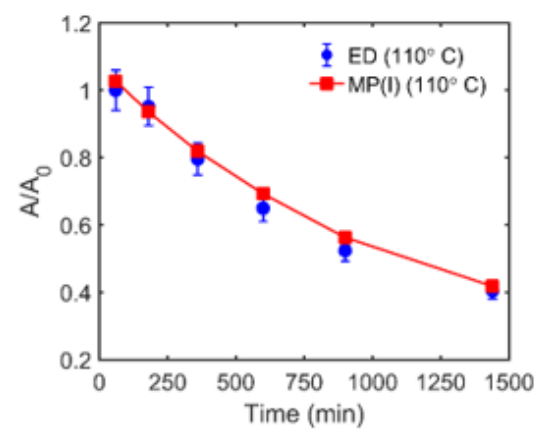

(b)

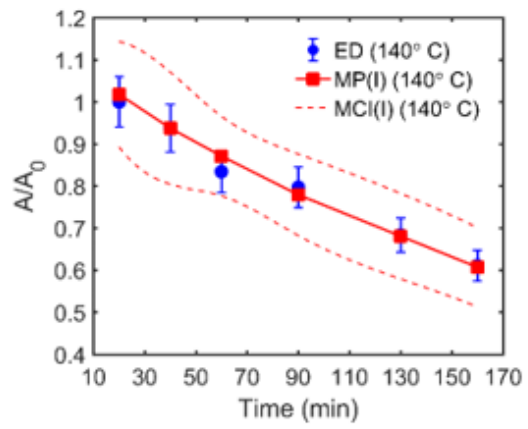

(d)

(e)

Figure 2: Predicted and experimental data at (a) 100, (b) 110, (c) 130, (d) 140 and (e) $150{ }^{\circ} \mathrm{C}$ using model derived from Mechanism I (MCI (I) = model confidence interval using Mechanism I; MP (I) = model predictions using Mechanism I; ED = experimental data). 
Thermal Degradation of Functional Food: Modeling and Parameter Estimation $\mid 167$

Table 1: Parameter estimation results using Mechanism $\mathrm{I}^{a}$

\begin{tabular}{lcccccc}
\hline $\mathbf{T}\left({ }^{\circ} \mathbf{C}\right)$ & $\mathbf{k}_{A B}\left(\mathbf{m i n}^{-1}\right)$ & $\mathbf{k}_{A C}\left(\mathbf{m i n}^{-1}\right)$ & $\mathbf{k}_{C B}\left(\mathbf{m i n}^{-1}\right)$ & $\mathbf{F}_{O B J}$ & $\mathbf{X}_{I N F}^{2}$ & $\mathbf{X}_{S U P}^{2}$ \\
\hline $\mathbf{1 0 0}$ & $6.44 \cdot 10^{-9}$ & $2.80 \cdot 10^{-4}$ & 0.0404 & 0.53 & 0.0009 & 5.02 \\
$\mathbf{1 1 0}$ & $2.45 \cdot 10^{-4}$ & $6.04 \cdot 10^{-4}$ & 0.00922 & 0.80 & 0.22 & 9.35 \\
$\mathbf{1 3 0}$ & $3.23 \cdot 10^{-4}$ & 0.00245 & 0.067 & 0.08 & 0.0009 & 5.02 \\
$\mathbf{1 4 0}$ & $1.64 \cdot 10^{-5} \pm 0.0017$ & $0.0041 \pm 0.0109$ & $0.114 \pm 1.08$ & 0.79 & 0.22 & 9.35 \\
$\mathbf{1 5 0}$ & $1.30 \cdot 10^{-9} \pm 0.0019$ & $0.0074 \pm 0.0054$ & $0.0872 \pm 3.23$ & 4.24 & 0.22 & 9.35 \\
\hline
\end{tabular}

a. $\left(\mathrm{T}=\right.$ temperature, $\mathrm{F}_{O B J}=$ objective function, $\mathrm{X}_{I N F}^{2}=$ lower bound of chi-squared

distribution, $\mathrm{X}_{S U P}^{2}=$ upper bound of chi-squared distribution)

Table 2: Parameter estimation results using Mechanism II

\begin{tabular}{lcccc}
\hline $\mathbf{T}\left({ }^{\circ} \mathbf{C}\right)$ & $\mathbf{k}_{A B}\left(\mathbf{m i n}^{-1}\right)$ & $\mathbf{F}_{O B J}$ & $\mathbf{X}_{I N F}^{2}$ & $\mathbf{X}_{S U P}^{2}$ \\
\hline $\mathbf{1 0 0}$ & $0.00025 \pm 1.4 \cdot 10^{-5}$ & 0.99 & 0.22 & 9.35 \\
$\mathbf{1 1 0}$ & $0.00071 \pm 5.0 \cdot 10^{-5}$ & 9.70 & 0.83 & 12.83 \\
$\mathbf{1 3 0}$ & $0.00246 \pm 4.1 \cdot 10^{-5}$ & 0.78 & 0.22 & 9.35 \\
$\mathbf{1 4 0}$ & $0.00375 \pm 5.3 \cdot 10^{-4}$ & 1.87 & 0.83 & 12.83 \\
$\mathbf{1 5 0}$ & $0.00681 \pm 1.2 \cdot 10^{-3}$ & 10.86 & 0.83 & 12.83 \\
\hline
\end{tabular}

ing model and experimental uncertainties.

At this point, the remaining candidate model is only the model derived from Mechanism II. Table 2 presents the parameter estimation results using this model.

The temperature dependence on the reaction rate constant $k_{A * B}$ is quantified by the activation energy $E a\left(\mathrm{KJ} \mathrm{mol}^{-1}\right)$ and is expressed by the Arrhenius equation represented in Equation (11). This effect of temperature on the kinetic constant $k_{A * B}$ is shown in Figure 5 . It can be observed that the estimated kinetic parameters follow the Arrhenius correlation very closely since the rate constants increase with the increase of reaction temperature. Linear regression, with a coefficient of determination $\left(R^{2}\right)$ equals to 0.9891 , was carried out to calculate the activation energy $\left(E_{a}\right)$ and pre-exponential factor $(A)$ for $k_{A * B}$ constant shown in Table 2. The obtained fits can also be observed in Figure 5 .

$$
K_{A^{*} B}=A \cdot \exp \left(-\frac{E a}{R T}\right)
$$

In the presented Equation (11), $T$ is the reaction temperature in Kelvin (K), $A$ is the preexponential factor expressed in the same units as $k_{A * B}$ and $R$ is the universal gas constant (8.314 $\mathrm{J} \mathrm{mol}^{-1} \mathrm{~K}^{-1}$ ).
For total all-trans- $\beta$-carotene degradation, a preexponential factor of $1.58 \cdot 10^{8} \mathrm{~min}^{-1}$ and an activation energy of $83.8 \mathrm{~kJ} \mathrm{~mol}^{-1} \mathrm{~K}^{-1}$ were found. Knockaert et al. (2012) reported a rate constant at $110^{\circ} \mathrm{C}$ of $0.10 \pm 0.01 \mathrm{~min}^{-1}$ and an activation energy of total $\beta$-carotene degradation for both an olive oil/carrot emulsion of $45.0 \pm 8.6$ $\mathrm{kJ} . \mathrm{mol}^{-1}$. On the other hand, Chen and Huang (1998) reported an activation energy equal to 39 $\mathrm{kJ} / \mathrm{mol}$ for total $\beta$-carotene degradation of an all-trans- $\beta$-carotene standard dissolved in hexane. Depending on the carotenoid source, as well as on the processing conditions and the reaction medium, a range from 20 to $171 \mathrm{~kJ} / \mathrm{mol}$ has been reported for the activation energy related to the thermal degradation of $\beta$-carotene (Achir et al., 2011; Achir et al., 2010; Penicaud et al., 2011; Sampaio et al., 2013). To the best of our knowledge, the kinetics of the thermal degradation of $\beta$-carotene in Acrocomia aculeata oil has not been investigated yet. Therefore, this result shows the thermal degradation kinetics for the all-trans- $\beta$-carotene in the oil agrees with those of previous studies carried out on other diverse sources of vegetable oils, since the activation energy estimated in the present study is indeed 


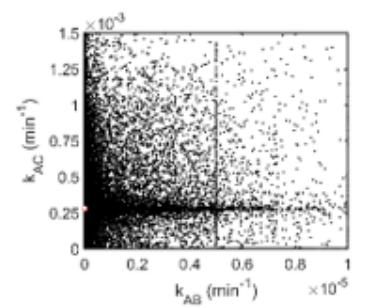

(a)

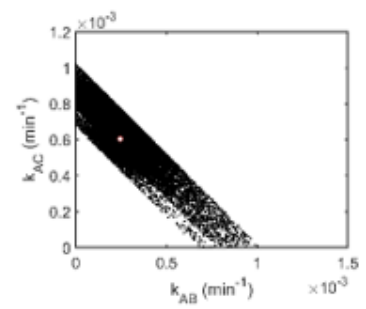

(d)

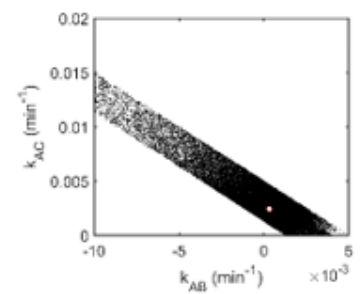

(g)

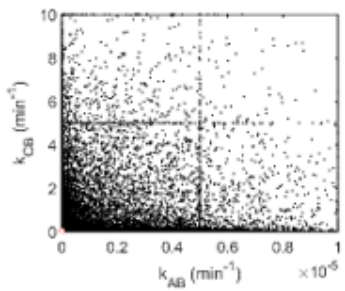

(b)

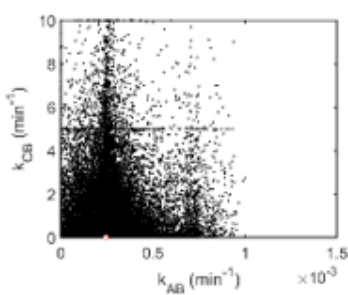

(e)

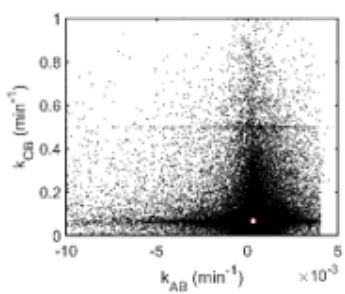

(h)

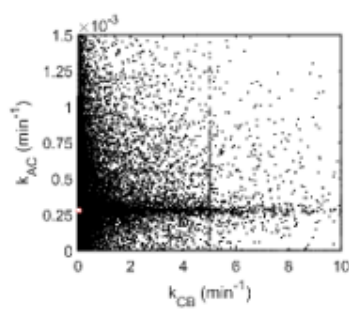

(c)

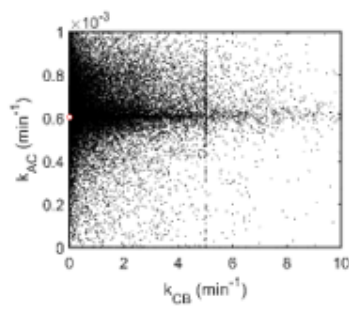

(f)

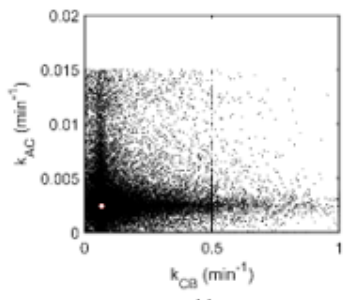

Figure 3: Parameters Confidence Regions, when Mechanism I was considered, at reaction temperature equals to (a), (b) and (c) $100^{\circ} \mathrm{C},(\mathrm{d}),(\mathrm{e})$ and (f) $110^{\circ} \mathrm{C},(\mathrm{g}),(\mathrm{h})$ and (i) $130{ }^{\circ} \mathrm{C}$.

within the range reported by other authors.

\section{Conclusion}

The thermal degradation predicted for the of all-trans- $\beta$-carotene in the Acrocomia aculeata oil was verified through mathematical modelling. On the one hand, the use of a kinetic mechanism with more than one reaction step is unnecessary since it results in an overparameterized model. On the other hand, the model developed with just one reaction channel can simulate all the experimental conditions directly and effectively, it adequately fitted the available data within the experimental errors. The activation energy and the pre-exponential factor calculated from the Arrhenius clearly shows the dependence of the reaction rate constant $k_{A * B}$ on temperat- ure. The developed model with a unique reaction can be suggested to be used as an effective tool to optimise process conditions not only in laboratory but also on industrial scale. This study has provided further information enabling better comprehension of the kinetics of thermal degradation of macauba oil, which is a promising source of high-quality raw materials.

\section{Acknowledgements}

The researchers gratefully acknowledged the Brazilian National Council for Scientific and Technological Development - CNPq for their financial support. The authors also wish to thank the Department of Chemical Engineering of the Federal University of Minas Gerais DEQ/UFMG/Brazil for providing facilities to 
Thermal Degradation of Functional Food: Modeling and Parameter Estimation | 169

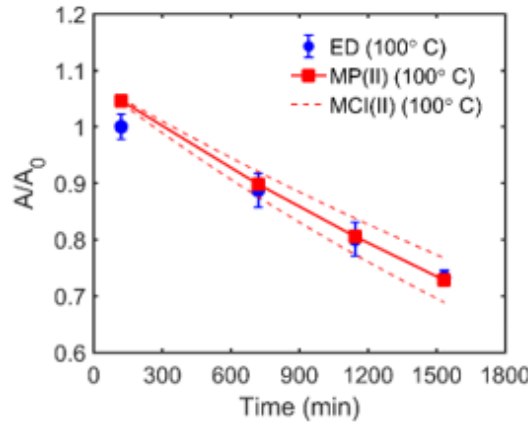

(a)

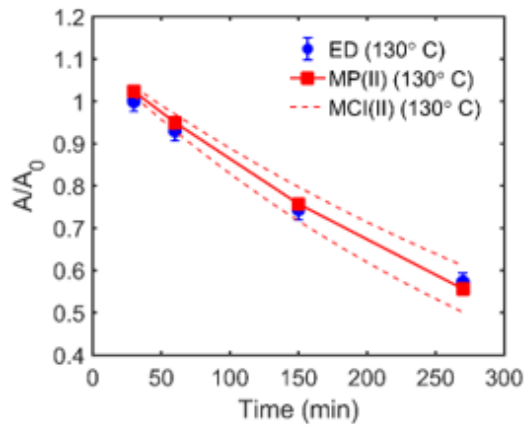

(c)

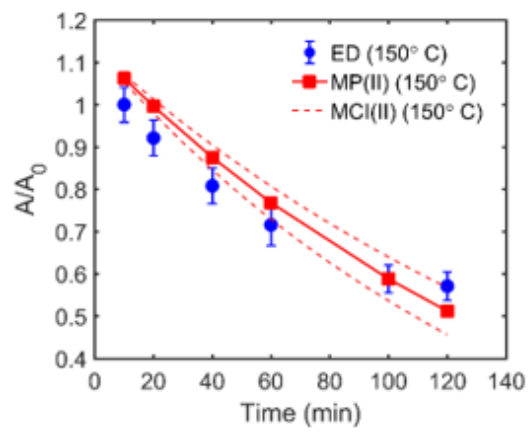

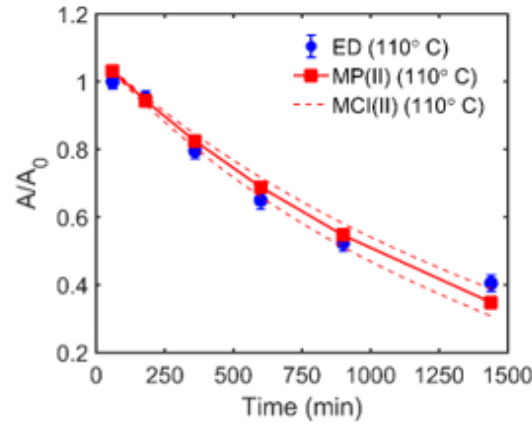

(b)

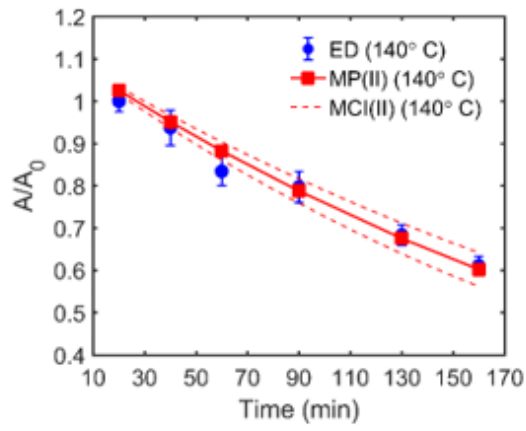

(d)

(e)

Figure 4: Predicted and experimental data at (a) 100, (b) 110, (c) 130, (d) 140 and (e) $150{ }^{\circ} \mathrm{C}$ using model derived from Mechanism II (MCI(II) = model confidence interval using Mechanism II; MP(II) = model predictions using Mechanism II; ED = experimental data). 


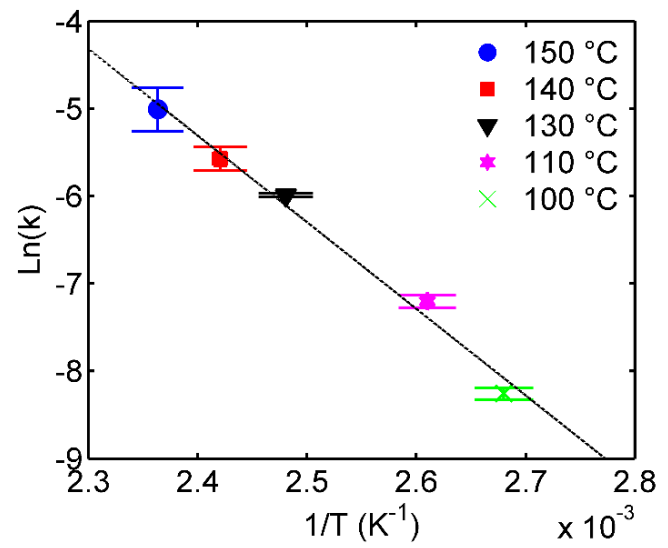

Figure 5: Arrhenius plot for the estimated model parameters at different thermal degradation temperatures using Mechanism II.

carry out this research.

\section{References}

Achir, N., Penicaud, C., Avallone, S. \& Bohuon, P. (2011). Insight into beta-carotene thermal degradation in oils with multiresponse modeling. Journal of the American Oil Chemists Society, 88(12), 2035-2045. doi:10.1007/s11746-011-1864-2

Achir, N., Randrianatoandro, V. A., Bohuon, P., Laffargue, A. \& Avallone, S. (2010). Kinetic study of beta-carotene and lutein degradation in oils during heat treatment. European Journal of Lipid Science and Technology, 112(3), 349-361. doi:10.1002/ ejlt.200900165

Ahmed, J., Shivhare, U. S. \& Sandhu, K. S. (2002). Thermal degradation kinetics of carotenoids and visual color of papaya puree. Journal of Food Science, 67(7), 2692-2695. doi:10.1111/j.1365-2621.2002. tb08800.x

Brandao, A. L. T., Oechsler, B. F., Gomes, F. W., Souza, F. G., Jr. \& Pinto, J. C. (2018). Modeling and parameter estimation of step-growth polymerization of poly(ethylene-2,5-furandicarboxylate).
Polymer Engineering and Science, 58(5), 729-741. doi:10.1002/pen.24605

Chen, B. H. \& Huang, J. H. (1998). Degradation and isomerization of chlorophyll a and beta-carotene as affected by various heating and illumination treatments. Food Chemistry, 62(3), 299-307. doi:10.1016/ S0308-8146(97)00201-X

Coimbra, M. C. \& Jorge, N. (2012). Fatty acids and bioactive compounds of the pulps and kernels of brazilian palm species, guariroba (syagrus oleraces), jeriva (syagrus romanzoffiana) and macauba (acrocomia aculeata). Journal of the Science of Food and Agriculture, 92(3), 679-684. doi:10 . $1002 /$ jsfa. 4630

Dhuique-Mayer, C., Tbatou, M., Carail, M., Caris-Veyrat, C., Dornier, M. \& Amiot, M. J. (2007). Thermal degradation of antioxidant micronutrients in citrus juice: Kinetics and newly formed compounds. Journal of Agricultural and Food Chemistry, 55(10), 4209-4216. doi:10 . 1021 / jf0700529

Evaristo, A. B., Saraiva Grossi, J. A., Pimentel, L. D., Goulart, S. d. M., Martins, A. D., dos Santos, V. L. \& Motoike, S. (2016). Harvest and post-harvest conditions influencing macauba (acrocomia aculeata) oil quality attributes. Industrial Crops and Products, 85, 63-73. doi:10.1016/j.indcrop. 2016.02.052

Goula, A. M. (2013). Ultrasound-assisted extraction of pomegranate seed oil - kinetic modeling. Journal of Food Engineering, 117(4), 492-498. doi:10.1016/j.jfoodeng.2012.10. 009

Henry, L. K., Catignani, G. \& Schwartz, S. (1998). Oxidative degradation kinetics of lycopene, lutein, and 9-cis and all-trans beta-carotenee. Journal of the American Oil Chemists Society, 75(7), 823-829. doi:10.1007/s11746-998-0232-3

Knockaert, G., Pulissery, S. K., Lemmens, L., Van Buggenhout, S., Hendrickx, M. \& Van Loey, A. (2012). Carrot beta-carotene degradation and isomerization kinetics during thermal processing in the presence of oil. Journal of Agricultural and Food Chem- 
Thermal Degradation of Functional Food: Modeling and Parameter Estimation $\mid 171$

istry, 60(41), 10312-10319. doi:10.1021/ jf3025776

Koidis, A. \& Boskou, D. (2015). Chapter 32 virgin olive oil: Losses of antioxidant polar phenolic compounds due to storage, packaging, and culinary uses. In V. Preedy (Ed.), Processing and impact on active components in food (pp. 267-274). doi:10. 1016/B978-0-12-404699-3.00032-9

Nunes, A. A., Favaro, S. P., Galvani, F. \& Miranda, C. H. B. (2015). Good practices of harvest and processing provide high quality macauba pulp oil. European Journal of Lipid Science and Technology, 117(12), 2036-2043. doi:10.1002/ejlt.201400577

Oloo, B. O., Shitandi, A. A., Mahungu, S., Malinga, J. B. \& Ogata, R. B. (2014). Effects of lactic acid fermentation on the retention of b-carotene content in orange fleshed sweet potatoes. International Journal of Food Studies, 3(1).

Palmero, P., Lemmens, L., Ribas-Agusti, A., Sosa, C., Met, K., Umutoni, J. d. D., .. Van Loey, A. (2013). Novel targeted approach to better understand how natural structural barriers govern carotenoid in vitro bioaccessibility in vegetable-based systems. Food Chemistry, 141(3), 20362043. doi:10.1016/j.foodchem.2013.05.064

Panfili, G., Fratianni, A. \& Irano, M. (2004). Improved normal-phase high-performance liquid chromatography procedure for the determination of carotenoids in cereals. Journal of Agricultural and Food Chemistry, 52(21), 6373-6377. PMID: 15478994. doi:10.1021/jf0402025

Parducci, L. G. \& Fennema, O. (1978). Rate and extent of enzymatic lipolysis at subfreezing temperatures. Cryobiology, 15(2), 199-204.

Penicaud, C., Achir, N., Dhuique-Mayer, C., Dornier, M. \& Bohuon, P. (2011). Degradation of beta-carotene during fruit and vegetable processing or storage: Reaction mechanisms and kinetic aspects: A review. Fruits, 66(6), 417-440. doi:10.1051/fruits/ 2011058

Petzold, L. R. (1982). Description of DASSL: a differential/algebraic system solver. Sandia National Labs., Livermore, CA (USA).
Pimenta, T. V. (2010). Metodologias de obtenção e caracterização dos óleos do fruto da macauba com qualidade alimentícia: Da coleta à utilização. $114 f$ (Doctoral dissertation, Dissertação (Mestrado em Engenharia Química)-Departamento de Engenharia).

Prates-Valerio, P., Celayeta, J. M. F. \& Cren, E. C. (2019). Quality parameters of mechanically extracted edible macauba oils (acrocomia aculeata) for potential food and alternative industrial feedstock application. European Journal of Lipid Science and Technology, 121(5). doi:10 . 1002 / ejlt . 201800329

Rodriguez-Amaya, D. B., Kimura, M. et al. (2004). Harvestplus handbook for carotenoid analysis. International Food Policy Research Institute (IFPRI) Washington.

Rodriguez-Amaya, D. B., Kimura, M., Godoy, H. T. \& Amaya-Farfan, J. (2008). Updated brazilian database on food carotenoids: Factors affecting carotenoid composition. Journal of Food Composition and Analysis, 21(6), 445-463. doi:10.1016/j . jfca.2008.04.001

Rodriguez-Amaya, D. B., Rodriguez, E. B. \& Amaya-Farfan, J. (2006). Advances in food carotenoid research: Chemical and technological aspects, implications in human health. Malaysian Journal of Nutrition, 12(1), 101-121.

Sampaio, K. A., Ayala, J. V., Silva, S. M., Ceriani, R., Verhe, R. \& Meirelles, A. J. A. (2013). Thermal degradation kinetics of carotenoids in palm oil. Journal of the American Oil Chemists Society, 90(2), 191-198. doi:10.1007/s11746-012-2156-1

Schieber, A. \& Carle, R. (2005). Occurrence of carotenoid cis-isomers in food: Technological, analytical, and nutritional implications. Trends in Food Science \& Technology, 16(9), 416-422. doi:10.1016/j.tifs . 2005.03.018

Schwaab, M., Biscaia, E. C., Jr., Monteiro, J. L. \& Pinto, J. C. (2008). Nonlinear parameter estimation through particle swarm optimization. Chemical Engineering Science, 63(6), 1542-1552. doi:10.1016/j.ces. 2007.11 .024 
$172 \mid$ Valério et al.

Zscheile, F. P., White, J. W., Beadle, B. W. \& Roach, J. R. (1942). The preparation and absorption spectra of five pure carotenoid pigments. Plant Physiology, 17(3), 331346. doi:10.1104/pp.17.3.331 